\title{
Peran Mediasi Brand Image Pada Green Promotion, Environmental Consciousness, Information Credibility Terhadap Purchase Decision
}

\author{
Qisthi Larasati ${ }^{1}$, Wisnalmawati ${ }^{2}$, Dyah Sugandini $^{3}$ \\ ${ }^{1}$ UPN Veteran Yogyakarta, larasatiqisthi95@gmail.com \\ ${ }^{2}$ UPN Veteran Yogyakarta, wisnalupnyk@ gmail.com \\ ${ }^{3}$ UPN Veteran Yogyakarta, dini@upnyk.ac.id
}

\begin{abstract}
This study aims to analyze the effect of green promotion, environmental consciousness, information credibility on purchase decisions mediated by brand image on environmentally-friendly cosmetic products The Body Shop in Yogyakarta. The variables used in this study are green promotion (X1), environmental consciousness $(X 2)$, information credibility (X3) purchase decision (Y), and brand image (Z). The population in this study are consumers who use The Body Shop products in Yogyakarta. The total sample in this study was 100 respondents using the convenience sampling technique or also known as accidental sampling and the data collection method using a questionnaire. The data analysis used was SEM (Structural Equation Model) analysis with the SMART PLS 3.2.7 program. By testing the hypothesis, the results of the analysis show that green promotion, environmental consciousness, information credibility has a positive effect on purchase decisions on The Body Shop products in Yogyakarta, and brand image can mediate the variables of green promotion, environmental consciousness, information credibility on purchase decisions. The suggestions for further researchers are because in this study there are still limitations so that further researchers are expected to be able to research with other variables and need to use a wider and more diverse range of respondents to obtain more varied results that can affect purchasing decisions.
\end{abstract}

Keywords: Brand Image, Environmental Consciousness, Green Promotion, , Information Credibility, Purchase Decision.

\begin{abstract}
ABSTRAK
Penelitian ini bertujuan untuk menganalisis pengaruh green promotion, environmental consciousness, information credibility terhadap purchase decisions yang dimediasi oleh brand image pada produk kosmetik ramah lingkungan The Body Shop di Yogyakarta. Variabel yang digunakan dalam penelitian ini green promotion $(X 1)$, environmental consciousness (X2), information credibility (X3) purchase decision (Y), dan brand image (Z). Populasi dalam penelitian ini adalah konsumen yang menggunakan produk The Body Shop di Yogyakarta. Jumlah sampel dalam penelitian ini sebanyak 100 responden dengan menggunakan teknik convenience sampling atau disebut juga accidental sampling dan metode pengumpulan datanya menggunakan kuesioner. Analisis data yang digunakan adalah analisis SEM (Structural Equation Model) dengan program SMART PLS 3.2.7. Dengan menguji hipotesis, hasil analisis menunjukkan bahwa green promotion, environmental consciousness, information credibility berpengaruh positif terhadap keputusan pembelian produk The Body Shop di Yogyakarta, dan brand image dapat memediasi variabel green promotion, environmental consciousness, information credibility atas purchase decisions. Saran bagi peneliti selanjutnya adalah karena dalam penelitian ini masih terdapat keterbatasan sehingga peneliti selanjutnya diharapkan dapat melakukan penelitian dengan variabel lain dan perlu
\end{abstract}


menggunakan responden yang lebih luas dan beragam untuk mendapatkan hasil yang lebih variatif yang dapat mempengaruhi keputusan pembelian.

Kata Kunci : Brand Image, Environmental Consciousness, Green Promotion, , Information Credibility, Purchase Decision.

Accepted:26-01-2021, Revision: 25-01-2021, Published: 01-04-2021

\section{PENDAHULUAN}

Saat ini pertumbuhan industri kosmetik di Indonesia terus berkembang pesat dengan kenaikan penjualan di tahun 2012 mencapai 14\% dengan angka Rp. 9,76 triliun dimana tahun sebelumnya sebesar Rp. 8,5 triliun. Persatuan Perusahaan Kosmetik Indonesia (PERKOSMI) dalam laman Kementerian Perindustrian Republik Indonesia pada tahun 2013 menyatakan industri kosmetik Indonesia terus tumbuh sebesar 15\% menjadi Rp.11,22 triliun. Pertumbuhan ini sejalan dengan meningkatnya konsumen kelas menengah sehingga daya beli semakin menguat. Untuk tahun 2016, nilai pasar industri kosmetik Indonesia melalui data Kementerian Perindustrian tumbuh 9\% yaitu Rp. 65,3 triliun dibanding tahun 2014 sebesar Rp. 59,03 triliun. Dan bahkan kementerian perindustrian mencatat pada 2017 pelaku industri kosmetik di Indonesia mencapai lebih dari 760 perusahaan. Dari total tersebut, sebanyak 95\% industri kosmetik nasional merupakan sektor industri kecil dan menengah (IKM). Namun dampak dari fenomena tersebut adalah meningkatnya limbah perindustrian yang akan menimbulkan permasalahan bagi lingkungan. Permasalahan sampah di Indonesia, dalam laman (www.geotimes.co.id) disebutkan bahwa sampah yang dihasilkan Indonesia keseluruhan sebanyak 175.000 ton per hari atau 0,7 kilogram per orang. Data statistik tahun 2014 mencatat sampah Indonesia menduduki peringkat kedua penghasil sampah plastik terbanyak setelah Cina.

Di Indonesia sendiri, terdapat beberapa regulasi yang berkaitan dengan lingkungan hidup, di antaranya yaitu Undang-Undang Pengelolaan Lingkungan Hidup no. 23 tahun 1997, Peraturan Pemerintah Republik Indonesia no. 4 tahun 2011 tentang pengendalian kerusakan dan atau pencemaran lingkungan hidup serta dukungan sistem manajemen lingkungan melalui penerapan ISO 14000 dan ISO 14020 mengenai ecolabeling. Eco-labeling atau label ramah lingkungan diberikan pemerintah sebagai salah satu bentuk dukungan untuk produk ramah lingkungan atau disebut sebagai green product sehingga green product dapat dengan mudah dibedakan dari produk konvensional di pasaran (M. D. F. Rahman, 2019). Dalam sektor usaha, upaya menjaga kelestarian lingkungan di wujudkan dengan go green pada berbagai bidang, yaitu pemasaran, produksi, maupun keungan. Dari sektor rumah tangga, konsumen dikenal istilah green consumerism (Utami, 2020). Dapat disimpulkan bahwa green consumerism muncul sebagai kesadaran global akan tanggung jawab mengurangi efek negatif konsumsi terhadap lingkungan. Mengingat kesadaran terhadap isu lingkungan cukup tinggi, semakin banyak pelaku bisnis yang menggunakan tema ramah lingkungan sebagai salah satu keunggulan produk mereka untuk menarik hati para green consumerism.

Salah satu perusahaan kosmetik dengan mengusung konsep produk yang ramah lingkungan adalah The Body Shop, yang mana perusahaan ini menawarkan 3 lini produk yakni body care, make up, dan fragrance (wewangian). Produk-produk yang ditawarkan berbahan alami, mengandung bahan baku pertanian organik, ramah 
lingkungan, no animal testing, dan sudah mendapatkan sertifikasi internasional. Konsep pemasaran ramah lingkungan pada The Body Shop juga dapat dilihat dari penggunaan kemasan yang dapat didaur ulang, serta penerapan program "bring back our bottle", dengan konsep perusahaan yang begitu sangat membantu dalam mengurangi limbah plastik (www.thebodyshop.co.id )

Penelitian ini menyajikan beberapa isu research gap yang dikemukakan pada penelitian sebelumnya. Isu yang pertama adalah green promotion dari hasil penelitian (F. Rahman et al., 2017) bahwa kegiatan iklan atau promosi yang dilakukan para pemasar tidak berpengaruh signifikan secara parsial terhadap keputusan pembelian, dikarenakan kurangnya sosialisasi terhadap produk ramah lingkungan. Sedangkan hasil penelitian (Geap et al., 2018) dari analisis data penelitian tersebut, promosi telah menempati variabel tertinggi dalam mempengaruhi keputusan konsumen dalam membeli green product. Isu yang kedua adalah tentang environmental consciousness atau kesadaran lingkungan. Berdasarkan penelitian (Lin \& Niu, 2018) menyatakan bahwa environmental consciousness merupakan faktor penting yang mempengaruhi keputusan pembelian produk hijau. Namun berdasarkan hasil penelitian (Rumpoko, 2016) menyatakan bahwa pengaruh variabel kepedulian konsumen terhadap lingkungan tidak berpengaruh secara signifikan terhadap keputusan pembelian dan dikatakan dalam penelitian tersebut masih banyak faktor lain yang mempengaruhi keputusan pembelian. Isu yang ketiga adalah tentang variabel information credibility Menurut penelitian (Agustini, 2017) menunjukan hasil penelitian bahwa kualitas informasi bukan merupakan faktor yang dominan dalam melakukan keputusan pembelian, karena terdapat faktor lain yaitu kualitas produk yang mana merupakan faktor paling dominan dalam konsumen membuat keputusan pembelian. Berdasarkan hasil penelitian dan pembahasan yang telah dilakukan oleh (Gao et al., 2016) yaitu dengan informasi yang berkualitas dan dapat dipercaya akan mempengaruhi pikiran bawah sadar dan konsumen dapat memikirkan setiap informasi yang masuk akal dan dengan demikian menghasilkan pemikiran yang tinggi untuk memutuskan membeli produk.

Dilihat dari fenomena dan hasil penelitian sebelumnya menunjukan adanya inkonsistensi hasil penelitian pengaruh green promotion, information credibility, dan environmental consciousness terhadap purchase decisions. Maka dari itu dalam penelitian ini memerlukan adanya variabel mediasi (intervening). Berdasarkan research gap yang telah ditemukan diatas mengenai pengaruh green promotion, environmental consciousness, information credibility terhadap purchase decision yang dimediasi oleh brand image pada produk The Body Shop di Yogyakarta maka dirasa perlu untuk dilakukan penelitian guna mengetahui pengaruh variabel-variabel tersebut.

\section{KAJIAN LITERATUR}

\section{Purchase Decision}

(Kotler \& Keller, 2016) mendefinisikan keputusan pembelian adalah mengidentifikasikan semua pilihan yang mungkin untuk memecahkan persoalan itu dan menilai pilihan-pilihan secara sistematis dan objektif serta sasaran yang menentukan keuntungan serta, kerugian masing-masing dan menyebutkan bahwa proses keputusan pembelian terdiri dari lima tahap, yaitu: pengenalan masalah, pencarian informasi, evaluasi alternatif, keputusan pembelian, dan pasca pembelian. Pada tahap keputusan pembelian, konsumen benar-benar melakukan pembelian.

\section{Environmental Consciousness}

Environmental consciousness atau kesadaran lingkungan setara dengan apa yang bisa terjadi dianggap sebagai sikap atau 
psikologis, perilaku pro-lingkungan yaitu, ia mencakup faktor-faktor endogen utama yang memiliki pengaruh terhadap perilaku. Namun, kita harus ingat bahwa perilaku prolingkungan sama-sama dipengaruhi oleh faktor non-sikap lainnya (eksogen atau situasional) (Golob \& Kronegger, 2019).

\section{Green Promotion}

Green promotion terdiri dari beberapa bagian yakni promosi yang membahas hubungan antara produk atau jasa dengan lingkungan biofisik, promosi yang mempromosikan gaya hidup ramah lingkungan dengan menyorot produk atau jasa tersebut,dan green promotion adalah promosi yang menyajikan citra perusahaan dari tanggung jawab lingkungan (Romdhoni et al., 2020). Green promotion berarti menyampaikan informasi tentang tanggung jawab lingkungan kepada konsumen yang mana hal tersebut merupakan komitmen perusahaan untuk melindungi lingkungan dan melindungi sumber daya alam (Mahmoud, 2018).

\section{Information Credibility}

Information credibility adalah informasi yang disampaikan harus dapat dipercaya. Kredibilitas informasi didefinisikan sebagai sejauh mana yang mana orang menganggap informasi dapat dipercaya dan salah satu kriteria yang digunakan untuk memfilter informasi yang tidak dapat dipercaya. Kredibilitas didefinisikan sebagai penilaian yang dibuat untuk mempersepsikan tentang kepercayaan seorang komunikator (Pasi \& Viviani, 2020).

\section{Brand Image}

Citra merek atau brand image adalah persepsi dan keyakinan yang dilakukan oleh konsumen. Citra merek umumnya didefinisikan segala hal yang terkait dengan merek yang ada dibenak ingatan konsumen (Kotler \& Keller, 2009). Citra merek merepresentasikan keseluruhan persepsi konsumen terhadap merek yang terbentuk karena informasi dan pengalaman konsumen terhadap suatu merek (Suryani, 2008).

\section{METODE PENELITIAN}

Penelitian ini termasuk dalam studi pengujian hipotesis. Adapun variabel yang digunakan dalam penelitian ini adalah green promotion (X1), environmental consciousness (X2), information credibility (X3) purchase decision $(Y)$ dan brand image $(Z)$. Populasi dalam penelitian ini ditentukan berdasarkan konsumen yang menggunakan produk dari The Body Shop. Sampel sebagai bagian dari populasi diperlukan dalam penelitian karena pertimbangan menghemat waktu, biaya dan tenaga (Saleh, 2017). Jumlah sampel dalam penelitian ini adalah 100 orang responden yang merupakan sebagian dari konsumen pengguna produk dari The Body Shop yang ada di Yogyakarta. Metode pengambilan sampel yang digunakan dalam penelitian ini adalah convience sampling. Convience sampling disebut juga accidental sampling yaitu metode pengambilan sampel dengan mendapatkan unit atau responden yang paling mudah diakses untuk menyediakan informasi yang dibutuhkan (Sekaran, 2011). Metode pengumpulan data dalam penelitian ini dengan instrumen kuesioner. Untuk uji instrumen penelitian menggunakan uji validitas dan uji reliabilitas dan untuk teknik analisis data yang digunakan adalah analisis SEM (Structural Equation Model) dengan program SMARTPLS 3.2.7.

\section{PEMBAHASAN}

\section{Analisis Structural Equation Modelling (SEM)}

Analisis ini dipilih untuk mengetahui pengaruh secara bertahap yaitu pengaruh green promotion, environmental consciousness, information credibility secara langsung terhadap purchase decision dan brand image dan pengaruh secara tidak langsung pengaruh green promotion, environmental consciousness, information credibility terhadap purchase decision melalui brand image pada produk The Body Shop di Yogyakarta. 
a. Uji validitas konstruk

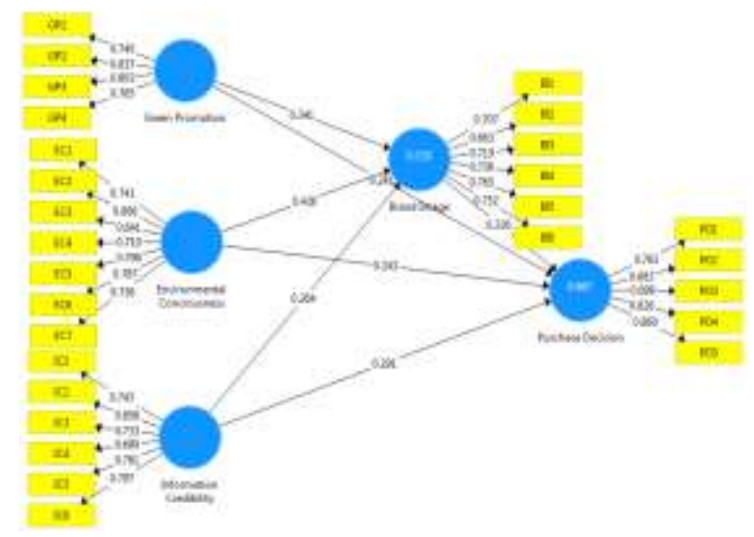

Sumber: Data Primer diolah Tahun 2020

Gambar 1. Hasil Analisis Validitas Konstruk

Berdasarkan gambar di atas terlihat bahwa semua loading factor nilainya di atas 0,5 . Dengan seluruh indikator pada variabel green promotion, environmental consciousness, information credibility, purchase decision dan brand image dapat dinyatakan valid.

\section{b. Uji Reliabilitas Kontruk}

Di samping validitas konstruk, dilakukan uji reliabilitas konstruk yang diukur dengan Composite reliability dari blok indikator yang mengukur konstruk. Konstruk dinyatakan reliabel jika nilai composite reliability di atas 0,70 (Ghozali, 2016).

Tabel 1. Hasil Pengujian Reliabilitas Konstruk

\begin{tabular}{llll}
\hline & $\begin{array}{l}\text { Cronbach's } \\
\text { Alpha }\end{array}$ & $\begin{array}{l}\text { Composite } \\
\text { Reliability }\end{array}$ & Keterangan \\
\hline Brand Image & 0.818 & 0.869 & Handal \\
\hline $\begin{array}{l}\text { Environmental } \\
\text { Conciousness }\end{array}$ & 0.856 & 0.891 & Handal \\
\hline $\begin{array}{l}\text { Green } \\
\text { Promotion }\end{array}$ & 0.801 & 0.870 & Handal \\
\hline $\begin{array}{l}\text { Information } \\
\text { Credibility }\end{array}$ & 0.859 & 0.895 & Handal \\
\hline $\begin{array}{l}\text { Purchase } \\
\text { Decision }\end{array}$ & 0.824 & 0.878 & Handal \\
$\begin{array}{l}\text { Sumber: Data Primer diolah Tahun } 2020 \\
\end{array}$ & &
\end{tabular}

Berdasarkan tabel di atas dapat diketahui bahwa semua konstruk mempunyai nilai composite reliability di atas 0,70 dan Alpha Cronbach's diatas 0,6. Dengan demikian maka dapat disimpulkan bahwa semua konstruk memenuhi persyaratan reliabilitas konstruk untuk dilakukan pengujian lebih lanjut. Model memberikan nilai R-square sebesar 0,720 pada variabel
Brand image, berarti bahwa kemampuan model pada variabel Green Promotion, Environmental Consciousness dan Information Credibility dalam menjelaskan variabel Brand image adalah sebesar $72 \%$ dan sisanya $28 \%$ dijelaskan oleh variabel lainnya. Sedangkan nilai $R$-square sebesar 0,867 pada variabel Purchase decision yang berarti bahwa kemampuan model pada variabel Green Promotion, Environmental Consciousness, Information Credibility dan Brand image dalam menjelaskan variabel Purchase decision sebesar $86,7 \%$ dan sisanya $13,3 \%$ dijelaskan oleh variabel lainnya. Di samping melihat nilai $R$-square, model PLS juga dievaluasi dengan melihat $Q$-square predictive relevance oleh model dan juga estimasi parameternya Koefisien Q2 sebesar 0,963 menunjukkan bahwa besarnya pengaruh total dari variabel Green Promotion, Environmental Consciousness, dan Information Credibility terhadap Purchase decision melalui Brand image adalah sebesar $96,3 \%$. Sedangkan sisanya sebesar $3,7 \%$ dijelaskan oleh variabel lainnya. Nilai Q2 > 0 menunjukkan model memiliki predictive relevance.

\section{Pengujian Hipotesis}

Pengujian hipotesis dilakukan dengan Analisis Jalur (Path Analysis). Analisis jalur adalah metode analisis data multivariat yang digunakan untuk menguji hipotesis dengan tujuan untuk mengetahui pengaruh langsung dan tidak langsung seperangkat variabel penyebab terhadap variabel akibat (Ghozali, 2013).

\begin{tabular}{|c|c|c|c|c|}
\hline & $\begin{array}{c}\text { Origin } \\
\text { al } \\
\text { Sampl } \\
\text { e }(\mathbf{O})\end{array}$ & $\begin{array}{c}\text { T } \\
\text { Statisti } \\
\text { cs } \\
(\mid \mathrm{O} / \mathrm{ST} \\
\text { DEV|) }\end{array}$ & $\begin{array}{c}\mathbf{P} \\
\text { Values }\end{array}$ & Keterangan \\
\hline $\begin{array}{l}\text { Green } \\
\text { Promotion } \\
\text {-> } \\
\text { Purchase } \\
\text { Decision }\end{array}$ & 0.241 & 3.615 & 0.000 & H1 didukung \\
\hline $\begin{array}{l}\text { Informati } \\
\text { on } \\
\text { Credibilit } \\
\text { y -> } \\
\text { Purchase } \\
\text { Decision }\end{array}$ & 0.291 & 3.998 & 0.000 & H2 didukung \\
\hline $\begin{array}{l}\text { Environm } \\
\text { ental } \\
\text { Conciousn } \\
\text { ess -> }\end{array}$ & 0.243 & 3.720 & 0.000 & H3 didukung \\
\hline
\end{tabular}




\section{Purchase}

Decision

Sumber: Data Primer diolah Tahun 2020

Tabel di atas menunjukkan pengaruh langsung antar konstruk:

a. Pengaruh green promotion terhadap purchase decision didapatkan nilai koefisien estimasi sebesar 0,241 dan $\mathrm{t}$ hitung sebesar 3,615 dan probabilitas sebesar $0,000<0,05$, maka dapat disimpulkan ada pengaruh yang signifikan secara langsung antara green promotion terhadap purchase decision. Dengan demikian maka hipotesis (H1) yang mengatakan " H1: Green promotion berpengaruh positif terhadap purchase decision" dapat didukung.

b. Pengaruh information credibility terhadap purchase decision didapatkan nilai koefisien estimasi sebesar 0,291 dan t hitung sebesar 3,998 dan probabilitas sebesar $0,000<0,05$, maka dapat disimpulkan ada pengaruh langsung secara signifikan antara information credibility dengan purchase decision pada produk The Body Shop di Yogyakarta. Dengan demikian maka hipotesis (H2) yang mengatakan " $\mathrm{H} 2$ : Information credibility berpengaruh positif terhadap purchase decision" dapat didukung.

c. Pengaruh environmental consciousness terhadap purchase decision didapatkan nilai koefisien estimasi sebesar 0,243 dan t hitung sebesar 3,720 dan probabilitas sebesar $0,000<0,05$, maka dapat disimpulkan ada pengaruh langsung secara signifikan antara environmental consciousness dengan purchase decision pada produk The Body Shop di Yogyakarta. Dengan demikian maka hipotesis (H3) yang mengatakan " $\mathrm{H} 3$ : Environmental consciousness berpengaruh positif terhadap purchase decision" dapat didukung.

Tabel 3. Hasil Uji Hipotesis

\begin{tabular}{ccccc}
\hline Pola & \multicolumn{4}{c}{ Indirect Effect } \\
\cline { 2 - 5 } $\begin{array}{c}\text { hubungan } \\
\text { Variabel }\end{array}$ & $\begin{array}{c}\text { Koefisi } \\
\text { en }\end{array}$ & $\begin{array}{c}\mathrm{T} \\
\text { hitung }\end{array}$ & $\begin{array}{c}\mathrm{P} \\
\text { value } \\
\mathrm{S}\end{array}$ & $\begin{array}{c}\text { Keteranga } \\
\mathrm{n}\end{array}$ \\
\hline $\begin{array}{c}\text { Green } \\
\begin{array}{c}\text { Promotion -> } \\
\text { Brand Image }\end{array}\end{array}$ & 0.111 & 2.447 & $\mathbf{0 . 0 1 5}$ & $\begin{array}{c}\mathrm{H} 4 \\
\text { didukung } \\
\text { dan }\end{array}$ \\
\hline
\end{tabular}

\begin{tabular}{ccccc}
$\begin{array}{c}-> \\
\text { Purchase } \\
\text { Decision }\end{array}$ & & & & $\begin{array}{c}\text { Mediasi } \\
\text { Signifikan }\end{array}$ \\
\hline $\begin{array}{c}\text { Environment } \\
\text { al }\end{array}$ & 0.139 & 3.577 & $\mathbf{0 . 0 0 0}$ & H5 \\
$\begin{array}{c}\text { Conciousness } \\
\text {-> Brand }\end{array}$ & & & & $\begin{array}{c}\text { didukung } \\
\text { dan }\end{array}$ \\
Image -> & & & & Mediasi \\
Purchase & & & & Signifikan \\
Decision & & & & \\
\hline $\begin{array}{c}\text { Information } \\
\text { Credibility - }\end{array}$ & 0.086 & 2.141 & $\mathbf{0 . 0 3 3}$ & H6 \\
$>$ Brand & & & & didukung \\
Image -> & & & & dan \\
Purchase & & & & Mediasi \\
Decision & & & & Signifikan \\
\hline
\end{tabular}

Sumber: Data Primer diolah Tahun 2020

Berdasarkan tabel diatas menunjukan hubungan antar konstruk:

a. Pengujian mediating effect di atas dapat diketahui bahwa koefisien pengaruh tidak langsung green promotion terhadap purchase decision melalui brand image adalah sebesar 0,111 dengan uji signifikansi diperoleh nilai $\mathrm{t}$ hitung sebesar 2,447 dan nilai probabilitas sebesar 0,015 dimana nilai tersebut lebih kecil dari 0,05 (pada taraf signifikan 5\%), maka dapat disimpulkan bahwa brand image secara positif dan signifikan memediasi atas hubungan antara green promotion dengan purchase decision pada the body shop di yogyakarta. Dengan demikian maka hipotesis (H4) yang mengatakan "H4: green promotion berpengaruh positif terhadap purchase decision dengan brand image sebagai mediator" dapat didukung.

b. Hasil koefisien pengaruh tidak langsung environmental consciousness terhadap purchase decision melalui brand image adalah sebesar 0,139 dengan uji signifikansi diperoleh nilai $\mathrm{t}$ hitung sebesar 3,577 dan nilai probabilitas sebesar 0,000 dimana nilai tersebut lebih kecil dari 0,05 (pada taraf signifikan 5\%), maka dapat disimpulkan bahwa brand image secara positif dan signifikan memediasi atas hubungan antara environmental consciousness dengan purchase decision pada the body shop di yogyakarta.. Dengan demikian maka hipotesis (H5) yang mengatakan "H5: environmental consciousness berpengaruh positif terhadap purchase decision dengan brand image sebagai mediator" dapat didukung. 
Hasil koefisien pengaruh tidak langsung information credibility terhadap purchase decision melalui brand image adalah sebesar 0,086 dengan uji signifikansi diperoleh nilai $\mathrm{t}$ hitung sebesar 2,141 dan probabilitas sebesar 0,033 dimana nilai tersebut lebih kecil dari 0,05 (pada taraf signifikan 5\%), maka dapat disimpulkan bahwa brand image secara signifikan memediasi atas hubungan antara information credibility dengan purchase decision pada the body shop di yogyakarta.. Dengan demikian maka hipotesis (H6) yang mengatakan "H6: information credibility berpengaruh positif terhadap purchase decision dengan brand image sebagai mediator" dapat didukung.

\section{SIMPULAN}

Hasil analisis SEM PLS dapat disimpulkan bahwa green promotion, environmental consciousness, information credibility berpengaruh positif terhadap purchase decision pada produk The Body Shop di Yogyakarta. dan variabel brand image mampu sebagai mediasi antara variabel green promotion, environmental consciousness, information credibility terhadap purchase decision. Saran untuk peneliti selanjutnya yaitu dikarenakan dalam penelitian ini masih menemui keterbatasan, sehingga bagi peneliti selanjutnya diharapkan dapat meneliti dengan variabel-variabel lain dan perlu digunakan responden yang lebih luas dan beragam agar memperoleh hasil yang lebih bervariatif yang dapat berpengaruh terhadap keputusan pembelian. Misalnya menambah variabel harga, keunggulan produk (Rahayu et al., 2017) dan pengaruh sosial, kualitas persepsi, nilai keuntungan (Mandawala \& Gamage, 2019) terhadap keputusan pembelian pada produk ramah lingkungan

\section{REFERENSI}

Agustini, N. K. D. A. (2017). Analisis FaktorFaktor Yang Mempengaruhi Keputusan Membeli Di Online Shop Mahasiswa Jurusan Pendidikan Ekonomi Angkatan Tahun 2012. Jurnal Pendidikan Ekonomi Undiksha, 9(1), 127. https://doi.org/10.23887/jjpe.v9i1.19997
(2016). Understanding Online Purchase Decision Making: The Effects of Unconscious Thought, Information Quality, and Information Quantity. SSRN Electronic Journal, 1-35. https://doi.org/10.2139/ssrn.2853899

Geap, C. L., Bedong, J., Bedong, J., Bathmanathan, V., \& Nasonal, U. T. (2018). Green Marketing Mix on Purchase of Green Products. 4(12), 1-11.

Ghozali, I. (2013). Ghozali, Imam (2013). Aplikasi Analisis Multivariate Dengan Program IBM SPSS 21Update PLS Regresi. Semarang: Badan Penerbit Universitas Diponegoro.

Ghozali, I. (2016). Aplikasi Analisis Multivariate dengan Program IBM SPSS 23 . Edisi 8. Cetakan ke-8. Semarang: Badan Penerbit Universitas Diponegoro. 2011.

Golob, U., \& Kronegger, L. (2019). Environmental consciousness of European consumers: A segmentation-based study. Journal of Cleaner Production, 221, 1-9. https://doi.org/10.1016/j.jclepro.2019.02.1 97

Kotler, P., \& Keller, K. L. (2009). Manajemen pemasaran Jilid 1. In Jakarta.

Kotler, P., \& Keller, K. L. (2016). MarkKotler, P., \& Keller, K. L. (2016). Marketing Management. Global Edition (Vol. $15 \mathrm{E})$. https://doi.org/10.1080/089117609030225 56eting Management. In Global Edition.

Lin, S. T., \& Niu, H. J. (2018). Green consumption: Environmental knowledge, environmental consciousness, social norms, and purchasing behavior. Business Strategy and the Environment, 27(8), 1679-1688.

https://doi.org/10.1002/bse.2233

Mahmoud, T. O. (2018). Impact of green marketing mix on purchase intention. International Journal Of Advanced And Applied Sciences, 5(2), 127-135. https://doi.org/10.21833/ijaas.2018.02.020

Gao, J., Zhang, C., Wang, K., \& Ba, S. Mandawala, M. B. B. U., \& Gamage, T. C. 
(2019). "Factors Affecting Consumers" Green Product Purchase Decisions: With Special Reference to Green Household Electronic Products in Western Province of Sri Lanka"." International Research Journal of Advanced Engineering and Science, Volume 4(Issue 4), 222-228.

Pasi, G., \& Viviani, M. (2020). Information credibility in the social web: Contexts, approaches, and open issues. ArXiv.

Rahayu, L., Abdillah, Y., \& Mawardi, M. (2017). Pengaruh Green Marketing Terhadap Keputusan Pembelian Konsumen (Survei Pada Konsumen The Body Shop di Indonesia dan di Malaysia). Jurnal Administrasi Bisnis S1 Universitas Brawijaya, 43(1), 121-131.

Rahman, F., Siburian, P. S., \& A, G. N. (2017). Pengaruh Green Marketing Mix terhadap Keputusan Pembelian Konsumen Produk Tupperware di Samarinda The Influence of Green Marketing Mix on Consumer Purchase Decision of Tupperware Products in Samarinda. Forum Ekonomi, 19(1), 119-130.

Rahman, M. D. F. (2019). Analisis Eco-label Terhadap Minat Beli Konsumen pada Minuman Kemasan Produk Minuman Tahun 2004-2015. Prosiding Industrial Research Workshop and National Seminar, 10(1), 927-937.

Romdhoni, M., Leonardo Budi H, SE, M., \& Dheasey Amboningtyas, SE, M. (2020). an Awareness and Analysis Consumer Perception of Application of. Journal of Management, 6(6), 1-12.

Rumpoko, U. A. D. (2016). Efek Green awareness Terhadap Keputusan Pembelian Produk Ramah Lingkungan. Program Studi Manajemen Fakultas Ekonomi Universitas Negeri Yogyakarta.

Saleh, S. (2017). Analisis Data Kualitatif. Penerbit Pustaka Ramadhan, Bandung.

Sekaran, U. (2011). Research Methods for Business (Metodologi Penelitian Untuk Bisnis). In Metode Penelitian. implikasi pada strategi pemasaran. Erlangga.

Utami, K. S. (2020). Green Consumers Behavior: Perilaku Konsumen dalam Pembelian Produk Ramah Lingkungan. Jurnal Maksipreneur: Manajemen, Koperasi, Dan Entrepreneurship, 9(2), 209.

https://doi.org/10.30588/jmp.v9i2.499

Suryani, T. (2008). Perilaku Konsumen 